\title{
Body Image and Life Satisfaction in Amish, Catholic, and Non-Religious Women
}

Denise Davidson

Associate Professor

Department of Psychology

Loyola University Chicago

Kelly S. Hughes

Auburn University

\author{
Ieva Misiunaite \\ Loyola University Chicago \\ Elizabeth Hilvert \\ Loyola University Chicago
}

Alan Shuldiner
University of Maryland School of Medicine

\begin{abstract}
Dissatisfaction with one's appearance is commonplace in Western women. Body image dissatisfaction is believed to be a consequence of societal emphases on appearance reinforced through norms and media. However, some Amish cultural values and norms differ from prevailing Western influences, which may result in a rate of body image dissatisfaction at variance within women. The following pilot study explores how religious affiliation and religiosity may relate to body image factors (body dissatisfaction, appearance investment, and body image coping strategies) and life satisfaction in Amish $(n=32)$, Catholic $(n=40)$, and nonreligious $(n=40)$ women. Results show that the Amish women reported having more positive body image on several factors than Catholic women, but the same results were not always replicated in non-religious women. Specifically, non-religious women showed similar levels of body satisfaction in comparison to Amish women, although they demonstrated use of different body image coping strategies. Additionally, when comparing women's reported current versus ideal figure, all women showed a preference for a thinner ideal. As this pilot study's methodology is preliminary, our ability to draw definitive conclusions is limited: future research should address these methodological limitations. If results from this study are confirmed, research is needed that examines the specific aspects of the Amish culture that may be associated with higher rates of body image satisfaction.
\end{abstract}

\section{Keywords}

Amish women; Body image; Life satisfaction 


\section{Introduction}

Body image is the perception, appraisal, and acceptance of one's own appearance (Cash and Smolak 2012). In the U.S., negative body image is so widespread among women that it is often referred to as a "normative discontent" (Cash and Henry 1995; Grogan 2007; Rodin, Silberstein, and Striegel-Moore 1985). This is troublesome because negative body image has been implicated as a significant factor that can lead to serious psychological disorders, including anorexia nervosa, binge eating, body dysmorphic disorder, and bulimia nervosa (APA 2013; Cash 2012). Even at non-clinical levels, negative body image has been associated with a high prevalence of disordered eating in the U.S., with up to $70 \%$ of young women engaging in some form of disordered eating (e.g., Fitzsimmons-Craft, Harney, Brownstone, Higgins, and BardoneCone 2012). Additionally, anxiety and depression can occur as the result of body dissatisfaction and negative body image (e.g., Keel, Mitchell, Davis, and Crow 2001). Thus, there is a need to determine what factors or societal demands result in negative body image in women.

In particular, the Amish may take varying stances from American popular culture-where most studies on body image are conducted - on issues that have been shown to affect body image, such as technology, clothing, and work, and therefore may yield an interesting comparison to other groups. For example, the Amish value hard work because their agrarian lifestyle often demands able bodies to perform the physical activities associated with their lives. Consequently, strong healthy bodies may be valued over simply aesthetically pleasing ones, which may be weak (Jolly 2014).

However, to our knowledge only one previous study has explored body image - and in particular, body dissatisfaction - in Amish women. In their study, Platte and colleagues (2000) hypothesized that because the Amish are removed from Western culture and ideals, individuals in the Amish community might be spared from body image problems of non-Amish society. To assess this assumption, Platte and colleagues (2000) measured body dissatisfaction in Old Order Amish men and women. Body dissatisfaction was measured by the difference between an individual's actual body mass index (BMI) and the BMI they chose as their ideal. Among the Old Order Amish, young women, young men, and older men showed no body dissatisfaction, while older women were more dissatisfied with their bodies. Although the most vulnerable group for body dissatisfaction in non-Amish Western society are young women, it appeared that younger Old Order Amish women had avoided the pressures of Western society in desiring a thinner physique. Platte, et al. (2000) stated that the differences between ages is not clear but they may be because of common weight gain patterns in older women, number of pregnancies, and food preparation. This study's goal is to provide a comparative group, which Platte, et al. (2000) called for in future studies, and to provide updated findings from this now two decades old study.

\section{Background Literature: Body Image and Religion}

Although little research has examined the impact of the Amish lifestyle upon body image, previous research has shown that religiosity in general can be associated with a more positive body image (e.g., Chaker, Chang, and Larson 2015; Dunkel, et al. 2010; Homan and Boyatzis 2009). However, the mechanisms for this effect are not well understood. One possibility may be that religiosity and a religious identity protects against the objectification of one's body and overacceptance of the thin-ideal (e.g., Moradi and Huang 2008; Moradi and Varnes 2017; Tiggemann 
2013). For example, the tenets espoused in many religions such as Christianity - that the body is a gift from God or a temple to God - can run counter to negative body image (e.g., Boyatzis, Kline, and Backof 2007). Additionally, religions often discourage false pride, considering it selfidolatry. Moreover, a religious identity or affiliation with a particular religion may provide a woman with an identity removed from a strictly appearance-based one (Dunkel, et al. 2010).

In fact, a systematic review of studies examining the relation of religiosity, disordered eating, and body image concerns generally concluded that strong, internalized religious beliefs and a secure relationship with a higher power are associated with lower levels of disordered eating, psychopathology, and body image anxiety (e.g., Akrawi, Bartrop, Potter, and Touyz 2015). Religion has been shown to have a positive effect on body image in some studies. In a recent study, Homan and Lemmon (2016) found that the quality of a woman's perceived relationship with God moderated the relationship between frequent body-related comparisons and body appreciation. Women who engaged in body-related comparisons more frequently had lower body appreciation, but only if they felt unsure about God's love and responsiveness. Women who engaged in frequent body-related comparisons, but felt unconditionally loved and accepted by God, did not have lower body appreciation.

Additionally, studies assessing the relation between body image and religiosity have found that a greater religious identity helps protect women from the negative impact of Western body image ideals, especially undue pressure to look a certain way or subscribe to the thin-ideal (Dunkel et al. 2010; Homan and Lemmon 2016). However, most of the research that has been conducted has focused on Christian women who are immersed in Western culture. Further work is needed to examine body image in women who are separated from Western culture and how a strong religious identity and religiosity influence their thoughts about their bodies.

Indeed, it is possible that having a strong religious identity may increase the pressure to have a "healthy" body weight. As it has been noted, the Amish "believe that good health, both physical and mental, is a gift from God and requires careful stewardship on the part of the individual" (Good and Good 1995, p. 65). Although the Amish have their own unique Christian rituals and practices today, they share the same religious roots as other Christian sects that have traditionally shunned the deadly sins of gluttony and sloth (Lyman 1989). For example, several Christian weight loss diet books and programs have promoted the importance of having a slender figure as a means of showing glory to God (e.g., Gerber 2008; Gerber 2012). Thus, it is possible that body image and weight concerns will exist among all women in this study.

\section{Overview of the Present Study}

The overarching goal of this pilot study was to explore the role of religious affiliation and religiosity on body image factors in Amish, Catholic and non-religious women. Body image factors were assessed in terms of overall body satisfaction, appearance schemas such as the value women assign to appearance and appearance-related behaviors, and the manner in which women cope with body image challenges. Secondary goals were to assess the relation of body mass index and body image satisfaction with life satisfaction. Amish and Catholic women were chosen because both groups score high on religious identity and religious tradition (Cohen, Pierce, Chambers, Meade, Gorvine, and Koenig 2005: Kraybill, et al. 2013) which may promote better body image and life satisfaction. Consequently, we hypothesize that religious identity and religiosity will negatively relate to body image investment (i.e., negative appearance schema 
factors) and the use of unhealthy body image coping strategies (i.e., avoidance and appearance fixing), while it will positively relate to increased body image satisfaction and healthier strategies (i.e., positive rational acceptance and religious coping) and life satisfaction.

We also speculate that Amish women may be less prone to appearance comparison and appearance fixing behaviors because of their unique technology and clothing practices. For example, the Amish have dress prescriptions, with modesty as one of the core values in dress, which itself could impact self-image. We expect Amish women to report viewing a figure with a higher body mass index as ideal, report less body dissatisfaction (e.g., less discrepancy between their perceived ideal figure and their current figure), and less likely to report engaging in appearance comparison, appearance modification behaviors, and emotional investment in their appearance compared to Catholic and non-religious women. It is also predicted that Amish women will be more likely to employ healthier coping strategies (e.g., will engage in self-care) when experiencing negative situations surrounding their bodies and report higher life satisfaction.

Nevertheless, a perusal of Amish newspapers suggests that body image and weight loss may be a concern among the Amish, given the number of ads for weight loss supplements and herbal remedies in these media sources. These ads could be a result of the Amish wanting to take care of their health, or it could be that the Amish do in fact internalize the thin-ideal. Although it may seem that Amish women would not be exposed to as much media that idealizes thinness in women as Catholic and non-religious women, Amish do not live in isolation. Amish women are able to see advertisements and beauty magazines in places such as the supermarket, homes of their English friends, and billboards. Moreover, they may be exposed to mainstream beauty ideals by the people they meet in public, audiovisual media some may access, and books they may read. Additionally, studies have shown that weight gain and obesity-related disorders have increased over the past several decades for Amish women (Hairston et al. 2013). As a result, issues about weight and body image may be a part of the experience of Amish and non-Amish women alike; it is possible that no differences will emerge.

In summary, we hypothesized that the Amish would report investing less in their appearance, idealizing a heavier figure, and using healthier coping strategies than non-Amish women, although we are aware that some present practices could reduce differences. To test these hypotheses, we interviewed Amish, Catholic, and self-identifying non-religious women about their religiosity, life satisfaction, and body image satisfaction using standardized questionnaires.

\section{Methods}

\section{Participants}

A total of 112 women participated in the study. Women identified as Amish $\left(N=32 ; \mathrm{M}_{\mathrm{age}}=\right.$ 49.2), Catholic $\left(N=40 ; M_{a g e}=42.3\right)$, or non-religious $\left(N=40 ; M_{a g e}=25.6\right)$. Amish women were recruited from Amish communities in Nappanee, Indiana $(n=14)$ and Lancaster County, Pennsylvania $(n=18)$. Although women from these communities were selected, in part, because of their proximity to the researchers, a number of other factors entered into our decision to recruit from these areas. Both the Nappanee, Indiana, and Lancaster County, Pennsylvania, Old Order Amish communities are well established (see, e.g., Petrovich 2017). Each community 
consists of a number of Amish-owned businesses that provide goods (e.g., furniture, quilts, food products) to the non-Amish. Thus, superficial contact with non-Amish individuals is relatively common and made it possible to discuss the project with Amish business owners regarding the posting of recruitment signs in their establishments. Based on demographic data collected from the participants, a number of similarities were shared by Amish women: all were from households that drove buggies, wore conservative attire that was a part of the Amish lifestyle, and refrained from the use of grid electricity.

A number of recruitment procedures were used in the study. Specifically, Amish women in Nappanee were contacted for several months through ads that were placed in an Amish newspaper serving this community. We also recruited through signs placed in businesses that serve the Amish community (e.g., laundry mats) and Amish-owned businesses (e.g., grocery stores). The ads and signs informed women of the study and provided a postal mail address that they could contact in order to receive a packet of measures in the mail. Included in the packet was a large, stamped envelope that they could use to mail the packet back to the researchers. Once returned to the researchers, a handwritten note of thanks, along with twenty dollars in cash, was sent to the participant. Similar signs were placed in businesses in Lancaster, although the majority $(n=17)$ of women from this area were recruited through the Amish Research Clinic affiliated with the University of Maryland School of Medicine. These women were participating in a larger study on health and genetics at the university. Women in Lancaster also received \$20 dollars for their participation. Women who returned a packet through the post were asked a number of questions to establish that they were Amish (e.g., reporting their religious affiliation, answering "yes" to "Are you Amish?", and answering questions about their use of technology in the home, modes of transportation, and style of dress).

Catholic and non-religious women were recruited from Illinois, Indiana and Pennsylvania. Efforts were made to recruit Catholic and non-religious women from areas near to where the Amish were living through the use of signs and an offer of \$20 for participation. However, this yielded only a very small number of our total non-Amish participants $(n=3)$. Thus, recruitment procedures were extended to include college-age Catholic $(n=22)$ and non-religious $(n=25)$ participants from the undergraduate subject pool at the first author's affiliated university. These students received course credit or extra credit for their participation. Older Catholic $(n=15)$ and non-religious $(n=15)$ women were recruited through internet links to our research website and contact with different community organizations (e.g., churches), as well as through university students who distributed packets of measures to extended family members (e.g., aunts and other family members). In order to increase the number of non-religious women who participated, we also recruited through a flyer posted in our community and through a link to an atheist website online. Recruitment of non-religious women included both women with no religious affiliation and those women who identified themselves as atheist. However, we did not ask them to specify whether they were non-affiliated or an atheist. See Table 1 for additional participant information.

We encourage caution in interpreting results from this pilot study, as our sampling did not include a randomized procedure, our sample sizes are relatively small for statistical analysis, and we were unsuccessful in recruiting comparison samples from the same areas as the Amish. 


\section{Table 1: Participant Characteristics and Group Differences}

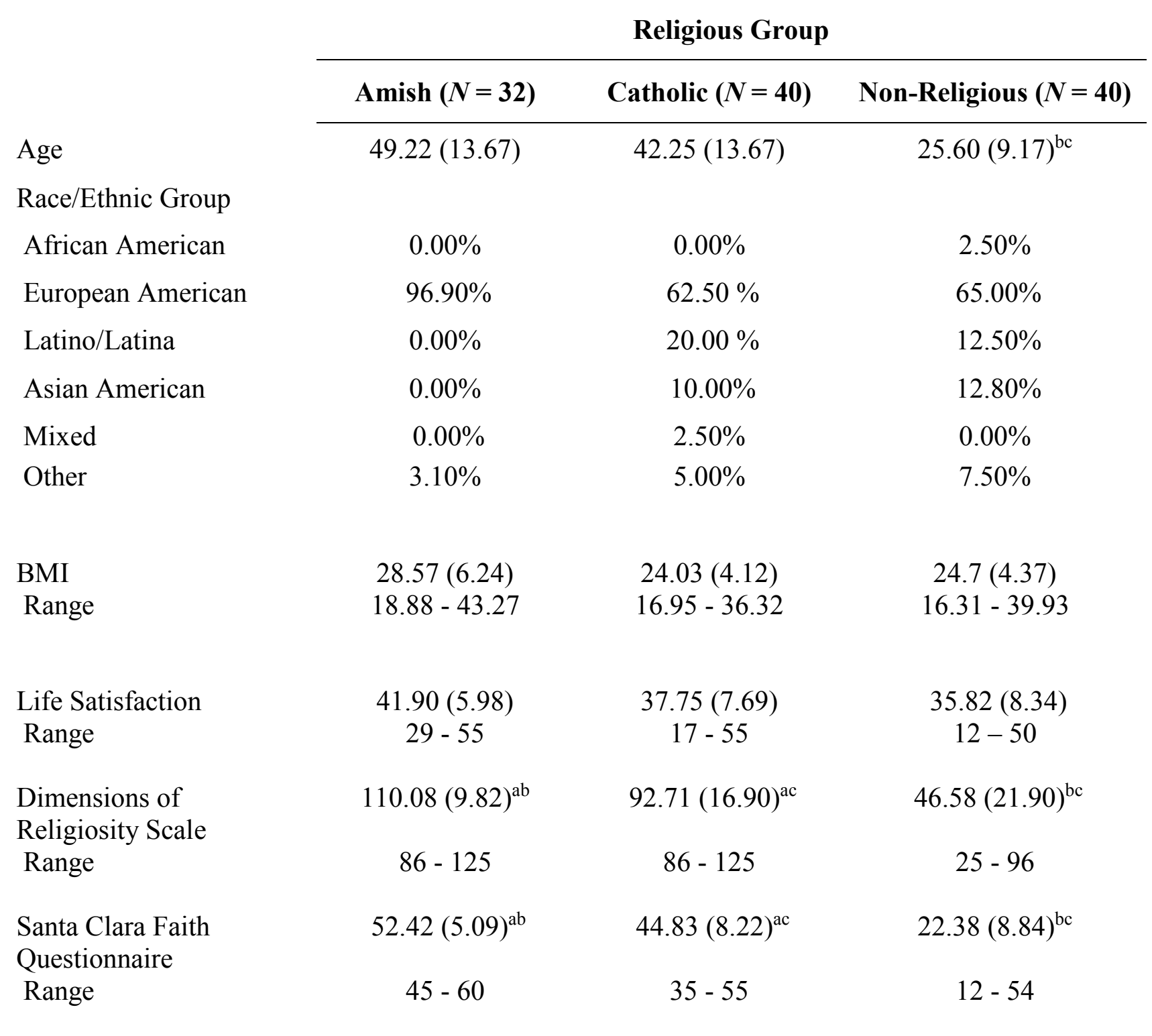

This pattern of results occurred with age as a co-variate.

a significant difference between Amish and Catholic women;

${ }^{\mathrm{b}}$ significant difference between Amish and non-religious women;

${ }^{c}$ significant difference between Catholic and non-religious women.

Higher religiosity scores reflect greater religiosity. Greater scores on the life satisfaction measure reflect more life satisfaction. The equation used to calculate BMI is as follows: (Weight in pounds/(Height in inches $\mathrm{x}$ height in inches))/703. BMI categories are distinguished accordingly: underweight $=<18.5$, normal weight $=18.5-24.9$, overweight $=25-29$, and obese $=<29($ CDC, 2017). Note that one woman, participant 153, listed her race as Other and specified it to be "Amish". 


\section{Measures}

\section{Religiosity and Life Satisfaction Measures}

Santa Clara Strength of Religious Faith Questionnaire. The Santa Clara Strength of Religious Faith questionnaire (SCSORF; Plante and Boccaccini 1997) is a 10-item self-report measurement of the strength of religious faith regardless of denomination. Examples of items on the SCSORF include "My religious faith is extremely important to me" and "I pray daily". The SCSORF has high internal reliability (Cronbach's Alpha $=.95)$ and split-half reliability $(r=.92$; Plante and Boccaccini 1997). In addition to Plante and Boccaccini's original questions, two additional items related to spirituality were developed for the present study. These items were as follows: "I consider myself a spiritual person, but not a religious one" and "I do not belong to any one religion." Each item is rated on a 5-point Likert scale, from 1 = "Strongly Disagree" to 5 $=$ "Strongly Agree".

The Dimensions of Religiosity Scale. The Dimensions of Religiosity Scale (DR Scale; Joseph and Diduca 2007) is a 20-item self-report measure which assesses four dimensions of religious thinking and behavior: (1) preoccupation; (2) guidance; (3) conviction; and (4) emotional involvement. Each item is rated on a 5-point Likert scale, from 1 = "Strongly Disagree" to 5 = "Strongly Agree", with the scoring reversed for negatively worded items. The DR Scale has high internal reliability (Cronbach's Alpha $=.95)$ and convergent validity $(r=.94)$. In addition to Joseph and Diduca's original questions, six additional items related to religiosity were added. The first five items were as follows: "I attend Mass/Service regularly", "I pray formalized prayer regularly", "My religion guides my daily life", "My religion is part of who I am", and "I would not be the same person without my religion". The final item asked participants how much they identified with their particular religious affiliation using a 5-point Likert scale, from $0=$ "Not At All" to 4 = "Very Much".

The Satisfaction with Life Scale. The Satisfaction with Life Scale (SWLS; Diener, Emmons, Larsen, and Griffin 1985) is a 5-item self-report measure designed to measure global cognitive judgments of satisfaction with one's life (Cronbach's Alpha $=.87 ; r=.82$ ). Each item is rated on a 7-point Likert scale, from $1=$ "Strongly Disagree" to $7=$ "Strongly Agree". The SWLS has high internal consistency and temporal reliability, as well as good construct validity (Diener, et al. 1985). In addition to Diener, et al.'s original questions, two additional items related to religion were developed for the present study. These items were as follows: "Personal life satisfaction is less important to me than serving God" and "It is important to me that my life serves God and his will."

\section{Body Image Measures}

Photographic Figure Rating Scale. The Photographic Figure Rating Scale (PFRS; Swami, Salem, Furnham, and Tovée 2008) is a self-report measure that is designed to capture women's overall body dissatisfaction. It consists of 10 black and white photographs of faceless women who range in body size from very thin to obese $(1=$ "Figure with lowest BMI" to $10=$ "Figure with the highest BMI"). Participants are asked to identify which photograph out of the 10 they believe best resembles their current body size, ideal body size, least ideal body size, and the body that represents the typical body for women their age. Additionally, in order to assess women's body dissatisfaction, the difference between the participant's current body size and ideal body 
size was calculated. Based on the difference between current and ideal body size, we also determined the percentage of women from each group who reported a desire to weigh less, weigh more, or remain the same. The PFRS has demonstrated good construct (Swami, et al. 2008) and convergent validity (Swami, Taylor and Carvalho 2011; Swami et al. 2012), as well as excellent test-retest reliability, $r=.89$ (Swami et al. 2008).

Appearance Schemas Inventory-Revised. The Appearance Schemas Inventory-Revised (ASI-R; Cash, Melnyck, and Hrabosky 2004) is a 20-item self-report measure designed to capture body image investment. Each item is rated on a 5-point Likert scale, from 1 = "Strongly Disagree" to 5 = "Strongly Agree". Although originally conceptualized as having two subscales (i.e., self-evaluative salience, motivation salience), recent confirmatory factor analyses with women (Chua, DeSantis, Teo, and Fingeret 2015; Davidson, Hilvert, Hughes, and Misiunaite 2018) provide evidence of three correlated subscales: appearance self-evaluation, appearance standards and behaviors, and appearance power/control. The appearance self-evaluation subscale examines the tendency an individual has to compare her appearance to others and be concerned with her looks. The appearance standards and behaviors subscale assesses the effort one puts into improving her looks and the ideals she holds regarding her appearance. The appearance power/control subscale measures the extent to which the individual believes her appearance has influence over her emotions and significantly impacts her life. According to Chua, et al. (2015), "Cronbach's alphas of .78, .77, and .72 for appearance self-evaluation, appearance power/ control, and appearance standards and behaviors, respectively, provided evidence of internal consistency reliabilities for the three subscales" (p. 5). A total score was also calculated, which reflects the overall importance appearance has in determining one's self-worth and sense of self (Giovannelli, Cash, Henson, and Engle 2008).

Body Image Coping Strategies Inventory. The Body Image Coping Strategies Inventory (BICSI; Cash, Santos, and Williams 2005) is a 29-item self-report measure that captures an individual's use of various coping strategies to deal with body image issues. Each item is rated on a 4-point rating scale, from $0=$ "Definitely Not Like Me" to $3=$ "Definitely Like Me". The BICSI is composed of three subscales, each identifying a unique coping strategy: avoidance, appearance fixing, and positive rational acceptance. The avoidance coping strategy involves avoiding threats to one's body image (e.g., "I make no attempt to cope or deal with the situation"). Appearance fixing refers to one's efforts to change her appearance by concealing or fixing a perceived physical flaw (e.g., "I spend extra time trying to fix what I don't like about my looks"). Positive rational acceptance refers to the activities that one engages in mentally and physically to promote self-care and realistic acceptance of one's physicality (e.g., "I remind myself of my good qualities"; Cash, et al. 2005). All three BICSI coping scales have good convergent validity with measures of body image evaluation and investment, as well as an individual's body mass index, Cronbach's Alpha $=.81$ (Cash, et al. 2005).

Additionally, we added three items reflecting the use of a religious identity coping style. Examples of a religious identity coping style included endorsement of several items including, "I believe that my body is a gift from God and I should feel good about it no matter what I look like" and "I am not concerned with my appearance because my belief and my religion has taught me that it is not important in life".

In addition to these measures, all women were asked to complete a demographic survey that asked them to provide age, race, religious affiliation, marital status, location of home, and 
height and weight. All participants were also asked questions about the style of dress they wore (e.g., dress lengths, plain or patterned fabric) and their use of technology in and out of the home.

\section{Procedure}

Before the study began, each recruitment method and all study procedures were subject to extensive review and approved by the Institutional Review Board at the authors' universities. All women provided informed consent; the Amish governing board of the newspaper carrying our advertisements provided additional consent. Amish business owners posting our flyers examined and approved all of our measures prior to posting our recruitment sign. After completing the demographic survey, the measures were provided to participants in a random order.

\section{Statistical Methods}

Preliminary analyses (ANOVAs) revealed a significant main effect of Age, $p=.0001$, $\eta_{p}{ }^{2}=.39$. Post-hoc analyses showed that non-religious women were significantly younger than Amish women, $p=.0001$, and Catholic women, $p=.0001$. Amish women and Catholic women did not differ in age, $p=.06$. Additionally, Amish women had a significantly higher body mass index (BMI) in comparison to Catholic women and non-religious women, $p=.004$. Because age and BMI were correlated with each other, and therefore multicollinearity existed between them, we did not include BMI as a covariate. More specifically, when running models with and without age and BMI, we found that the model with BMI accounted for less variance. Therefore, only age was used as a covariate (ANCOVA) in all subsequent analyses with religious group comparisons. That is, separate ANCOVAs with age as a covariate were conducted for the religiosity scales (Santa Clara Strength of Religious Faith Questionnaire and the Dimensions of Religiosity Scale) and all of the body image measures (Photographic Figure Rating Scale, the Appearance Schemas Inventory-Revised, and the Body Image Coping Strategies Inventory). The Bonferroni correction method was used with all follow-up analyses from the ANCOVA tests.

Finally, to explore the relations between religious group and body image and life satisfaction factors, a total score was first created that combined women's responses from the Dimensions of Religiosity Scale and the Santa Clara Strength of Faith Questionnaire. Given that different scales were used in each questionnaire, women's Z-scores from each questionnaire were combined to form an overall religiosity score. Pearson correlation analyses between this score and each body image measure were conducted separately for each religious group.

\section{Results}

\section{Analysis of Religious Group Differences on Religiosity and Life Satisfaction Measures}

\section{Religiosity}

When examining religiosity as determined by the SCSORF questionnaire, a significant main effect of Religious Group, $p=.0001, \eta_{p}{ }^{2}=.59$, was found. Amish women scored significantly higher on their strength of religious faith compared to Catholic women, $p=.001$, and non-religious women, $p=.0001$. Catholic women also scored higher on strength of religious faith compared to non-religious women, $p=.0001$. 
Taking a closer look at women's responses to the following questions that had been added to the SCSORF - "Q23: My religion guides my daily life"; "Q24: My religion is part of who I am"; and "Q25: I would not be the same person without my religion" revealed that non-religious women agreed less strongly with all three statements compared to Amish women, $p<.0001$, and Catholic women, $p<.0001$. Moreover, Amish women agreed more strongly with "My religion guides my daily life" than Catholic women, $p=.02$.

Likewise, a significant main effect of Religious Group was found on the total score on the DR Scale, $p=.0001, \eta_{p}{ }^{2}=.52$. Post hoc tests showed that Amish women scored significantly higher on the dimensions of religiosity scale compared to Catholic women, $p=.005$, and nonreligious women, $p=.0001$. Moreover, Amish and Catholic women scored higher on religiosity compared to non-religious women, $p=.0001$.

\section{Life Satisfaction}

When comparing women's rating of life satisfaction, no significant differences in reports of life satisfaction were found between religious groups, $p=.17, \eta_{p}{ }^{2}=.03$. However, differences were found in terms of the following religious-based life satisfaction items - "Q5: Personal life satisfaction is less important to me than serving God" $\left(p=.0001 \eta_{p}^{2}=.21\right)$ and "Q9: It is important to me that my life serves God and his will" $\left(p=.0001 \eta_{p}{ }^{2}=.45\right)$. Amish women agreed more strongly with both statements than Catholic women, $p<.0001$, and non-religious women, $p<.0001$. Moreover, Catholic women agreed more strongly with these statements than non-religious women, $p<.0001$.

\section{Analysis of Religious Groups Differences on Body Image Measures}

Controlling for Age across all tests, a main effect of Religious Group was found on the Photographic Figure Rating Scale for current body size, $, p=.01, \eta_{p}{ }^{2}=.08$. Amish women reported a greater body size on the PFRS compared to Catholic women, $p=.01$. Note that this finding matches what they reported in terms of BMI. Significant differences were also found between religious groups for ideal body size, $p=.0001, \eta^{2}=.20$. Catholic women's ideal body size was smaller than Amish women, $p=.001$, and non-religious women, $p=.002$. However, religious groups did not differ in their rating of least ideal body size, $p=.88, \eta_{p}{ }^{2}=.002$, body dissatisfaction, $p=.49, \eta_{p}{ }^{2}=.01$, or their desire to weigh less, $p=.30, \Phi=.26$. See Table 2 for means and standard deviations for each group.

On the Appearance Schemas Inventory-Revised, our analyses revealed a main effect of Religious Group for appearance power/control, $p=.04, \eta_{p}{ }^{2}=.07$. Amish women scored significantly lower on the appearance power/control subscale of the ASI-R compared to Catholic women, $p=.04$, indicating that Amish women were less likely to feel that their appearance has influence over their emotions and their life in general. No other significant effects were found for the ASI-R. See Table 2 for means and standard deviations.

In terms of strategies for coping with body image challenges, our analyses revealed a main effect of Religious Group for the appearance fixing coping strategy, $p=.03, \eta_{p}{ }^{2}=.07$. Amish women reported using the appearance fixing coping strategy less than Catholic women, $p=.02$. No significant differences were found between Amish women and Catholic women for the use of this religious identity coping strategy, $p=.07$. No main effects of Religious Group were found 


\section{Table 2: Comparison of Religious Groups on Body Image Measures}

\begin{tabular}{|c|c|c|c|}
\hline \multirow[b]{3}{*}{$\begin{array}{l}\text { Photographic Figure Rating } \\
\text { Scale }\end{array}$} & \multicolumn{3}{|c|}{ Religious Group } \\
\hline & $\begin{array}{c}\text { Amish } \\
(N=32)\end{array}$ & $\begin{array}{l}\text { Catholic } \\
(N=40)\end{array}$ & $\begin{array}{c}\text { Non-Religious } \\
\quad(N=\mathbf{4 0})\end{array}$ \\
\hline & & & \\
\hline Current Body Size & $6.71(2.10)^{\mathrm{a}}$ & $4.82(2.11)^{\mathrm{a}}$ & $5.11(2.47)$ \\
\hline Ideal Body Size & $4.47(1.50)^{\mathrm{a}}$ & $2.87(1.23)^{\mathrm{ac}}$ & $3.58(1.43)^{\mathrm{c}}$ \\
\hline Least Ideal Body Size & $8.50(3.41)$ & $9.08(2.60)$ & $9.53(1.99)$ \\
\hline Typical Body Size for Age & $6.27(1.38)^{\mathrm{a}}$ & $4.97(1.49)^{\mathrm{a}}$ & $4.73(1.32)$ \\
\hline $\begin{array}{l}\text { Body Dissatisfaction Score } \\
\text { (Current - Ideal Body Size) }\end{array}$ & $2.20(1.55)$ & $1.92(1.36)$ & $1.89(1.75)$ \\
\hline \multicolumn{4}{|l|}{ Weight Preferences } \\
\hline Desire to Weigh Less & $87 \%$ & $84 \%$ & $82 \%$ \\
\hline Desire to Weigh More & $0 \%$ & $0 \%$ & $3 \%$ \\
\hline Desire to Remain the Same & $13 \%$ & $6 \%$ & $15 \%$ \\
\hline \multicolumn{4}{|l|}{ ASI-R* } \\
\hline Self-Evaluation & $19.94(4.91)$ & $23.53(6.04)$ & $25.78(6.59)$ \\
\hline Power/Control & $11.44(3.50)^{\mathrm{a}}$ & $14.67(3.44)^{\mathrm{a}}$ & $14.38(3.92)$ \\
\hline Standards and Behavior & $22.28(4.11)$ & $24.88(5.90)$ & $25.23(4.51)$ \\
\hline ASI-R Total Score & $52.67(11.37)$ & $63.08(12.34)$ & $65.38(12.76)$ \\
\hline \multicolumn{4}{|l|}{ BICSI } \\
\hline Avoidance & $7.04(2.88)$ & $6.72(4.30)$ & $6.65(3.90)$ \\
\hline Appearance Fixing & $5.57(4.21)^{\mathrm{a}}$ & $8.90(4.31)^{\mathrm{ac}}$ & $9.77(3.82)^{\mathrm{c}}$ \\
\hline Positive Rational Acceptance & $17.14(5.81)$ & $19.90(5.65)$ & $19.38(5.03)$ \\
\hline Religious Identity & $7.89(2.47)^{\mathrm{b}}$ & $6.13(2.98)^{\mathrm{c}}$ & $3.08(1.88)^{b c}$ \\
\hline
\end{tabular}

This pattern of results occurred after age was co-varied out.

ASI-R = Appearance Schemas Inventory, Revised.

BICSI = Body Image Coping Strategy Inventory.

a significant difference between Amish and Catholic women;

$\mathrm{b}$ significant difference between Amish and non-religious women;

${ }^{c}$ significant difference between Catholic and non-religious women.

Higher scores on each of the ASI-R and BICSI subscales indicates greater use of each respective strategy. 


\section{Table 3: Correlations Between Religiosity Z-score and Body Image Measures}

\begin{tabular}{lccc}
\hline & \multicolumn{3}{c}{ Religiosity } \\
\cline { 2 - 3 } & Amish & Catholic & Non-Religious \\
\cline { 2 - 3 } PFRS Current Body Size & 0.30 & 0.23 & -0.24 \\
PFRS Discrepancy Score & 0.18 & 0.22 & 0.02 \\
ASI-R Appearance Self-evaluation & $-0.73^{*}$ & 0.02 & $-0.41^{*}$ \\
ASI-R Appearance Power/Control & -0.36 & -0.08 & -0.21 \\
ASI-R Appearance Standards and Behaviors & -0.18 & -0.19 & $-0.39^{*}$ \\
BICSI Avoidance Coping & $-0.66^{* *}$ & 0.19 & -0.21 \\
BICSI Appearance Fixing Coping & -0.18 & 0.06 & $-0.41^{*}$ \\
BICSI Positive Rational Acceptance Coping & -0.07 & 0.12 & 0.14 \\
BICSI Religious Identity Coping & 0.22 & $0.67^{* * *}$ & $0.65^{* * *}$ \\
\hline
\end{tabular}

PFRS $=$ Photographic Figure Rating Scale.

ASI-R = Appearance Schemas Inventory, Revised.

BICSI $=$ Body Image Coping Strategy Inventory.

${ }^{*} p<.05 ;{ }^{* *} p<.01 ;{ }^{* * *} p<.001$.

Positive correlations reflect greater Z-scores on religiosity and higher values on the PFRS, ASI-R, and BICSI factors, whereas negative correlations reflect greater Z-scores on religiosity and lower values on the PFRS, ASI-R, and BICSI factors.

for women's use of the avoidance coping strategy, $p=.82, \eta_{p}{ }^{2}=.004$. Non-religious women, however, showed greater positive rational acceptance coping strategy than the other groups, $p=$ $.01, \eta_{p}^{2}=.05$ (see Table 2).

\section{Relations between Religiosity, Body Mass Index, Life Satisfaction and Body Image Measures}

As shown in Table 3, for Amish women, greater religiosity scores were negatively correlated with scores on the appearance self-evaluation subscale of the ASI-R and the avoidance coping strategy subscale of the BICSI. For Catholic women, religiosity was positively correlated with their use of the religious identity coping strategy (see Table 3 for correlation values). As shown in Table 4, greater BMI was related to greater body dissatisfaction in all women as reported on the Photographic Figure Rating Scale. Finally, in terms of life satisfaction, for Catholic and non-religious women, life satisfaction was negatively related to their scores on the appearance self-evaluation subscale and their scores on the appearance power/control subscale of the ASI-R (see Table 5). Life satisfaction scores were not correlated with any of the subscales on the appearance inventory measure (ASI-R) for Amish women. In terms of how women coped with body image challenges, Pearson correlation analyses showed that in all women, those who 


\section{Table 4: Correlations Between BMI and Body Image Measures}

\begin{tabular}{lccc}
\hline & \multicolumn{3}{c}{ BMI } \\
\cline { 2 - 4 } & Amish & Catholic & Non-Religious \\
\cline { 2 - 4 } PFRS Current Body Size & $0.66^{* * *}$ & $0.89^{* * *}$ & $0.81^{* * *}$ \\
PFRS Discrepancy Score & $0.5^{* *}$ & $0.68^{* * *}$ & $0.58^{* * *}$ \\
$\begin{array}{l}\text { ASI-R Appearance Self- } \\
\text { evaluation }\end{array}$ & 0.17 & -0.16 & -0.09 \\
$\begin{array}{l}\text { ASI-R Appearance } \\
\text { Power/Control }\end{array}$ & -0.03 & $-0.39^{*}$ & -0.13 \\
$\begin{array}{l}\text { ASI-R Appearance Standards } \\
\text { and Behaviors }\end{array}$ & -0.12 & $-0.56^{* * *}$ & -0.26 \\
$\begin{array}{l}\text { BICSI Avoidance Coping } \\
\text { BICSI Appearance Fixing }\end{array}$ & 0.09 & 0.22 & 0.27 \\
$\begin{array}{l}\text { Coping } \\
\text { BICSI Positive Rational }\end{array}$ & -0.02 & -0.24 & -0.12 \\
$\begin{array}{l}\text { Acceptance Coping } \\
\text { BICSI Religious Identity }\end{array}$ & 0.28 & 0.17 & -0.18 \\
Coping & -0.13 & 0.17 & 0.01 \\
\hline
\end{tabular}

PFRS $=$ Photographic Figure Rating Scale .

ASI-R = Appearance Schemas Inventory, Revised.

BICSI = Body Image Coping Strategy Inventory.

${ }^{*} p<.05 ;{ }^{* *} p<.01 ;{ }^{* * *} p<.001$

Positive correlations reflect higher BMI and higher values on the PFRS, ASI-R, and BICSI factors, whereas negative correlations reflect higher BMI and lower values on the PFRS, ASI-R, and BICSI factors.

reported greater life satisfaction were less likely to use an appearance fixing coping strategy. For Amish women, life satisfaction was also positively correlated with their use of the religious identity coping strategy. For non-religious women, life satisfaction was negatively related to their use of the avoidance coping strategy and positively related to their use of the positive rational acceptance coping strategy (see Table 5 for correlation values).

\section{Discussion}

This pilot study explored whether the Amish lifestyle is associated with healthier body image and greater life satisfaction when comparing survey responses to Catholic and nonreligious women. Results indicated that for Amish, Catholic, and non-religious women, body dissatisfaction was negatively related to life satisfaction, which echoes past research that body image is a salient factor which impacts women's quality of life in Western society (Mercurio and Landry 2008; Stokes and Frederick-Recascino 2003). All groups also showed a positive correlation between body mass index (BMI) and body dissatisfaction, indicating that regardless of religious culture and/or affiliation, participants valued lower BMIs. 


\section{Table 5: Correlations Between Life Satisfaction and Body Image Measures}

\begin{tabular}{|c|c|c|c|}
\hline & \multicolumn{3}{|c|}{ Life Satisfaction } \\
\hline & Amish & Catholic & Non-Religious \\
\hline PFRS Current Body Size & -0.001 & 0.03 & -0.27 \\
\hline PFRS Discrepancy Score & -0.008 & -0.21 & -0.28 \\
\hline ASI-R Appearance Self-evaluation & -0.23 & $-0.36^{*}$ & $-0.52^{* * *}$ \\
\hline ASI-R Appearance Power/Control & -0.30 & $-0.35^{*}$ & $-0.55^{* * *}$ \\
\hline ASI-R Appearance Standards and Behaviors & -0.16 & -0.02 & -0.22 \\
\hline BICSI Avoidance Coping & -0.31 & -0.30 & $-0.63^{* * *}$ \\
\hline BICSI Appearance Fixing Coping & $-0.54^{* *}$ & $-0.43^{* *}$ & $-0.43^{* *}$ \\
\hline BICSI Positive Rational Acceptance Coping & 0.16 & 0.04 & $0.33^{*}$ \\
\hline BICSI Religious Identity Coping & $0.45^{*}$ & 0.11 & $0.33 *$ \\
\hline $\begin{array}{l}\text { PFRS }=\text { Photographic Figure Rating Scale. } \\
\text { ASI-R }=\text { Appearance Schemas Inventory, Revised. } \\
\text { BICSI = Body Image Coping Strategy Inventory. } \\
{ }^{*} p<.05 ;{ }^{* *} p<.01 ;{ }^{* * *} p<.001 \\
\text { Positive correlations reflect greater life satisfaction } \\
\text { negative correlations reflect greater life satisfaction }\end{array}$ & Hes on & , we & $\begin{array}{l}\text { actors, whereas } \\
\text { actors. }\end{array}$ \\
\hline
\end{tabular}

However, given the age differences between religious and non-religious women, and that older women typically have greater BMI than younger women (Tiggemann 2004), it will be important for future research to examine whether younger religious women show the same pattern. Additionally, with the exception of one participant from the non-religious group, no participants reported wishing to gain weight in order to embody their ideal figure, while over $80 \%$ of individuals from each group reported that they wanted to lose weight.

Results also indicated that Amish women did indeed report some advantageous aspects pertaining to body image in comparison to Catholic women. Specifically, Amish women were more likely to choose a figure with a higher BMI as ideal, were less likely to report that their appearance influenced their emotions, and were less likely to report using the appearance fixing body image coping strategy than Catholic women. Thus, while Amish and Catholic women alike are exposed to religious messages, it is possible that areas of Amish culture may protect Amish women from fully internalizing the thin-ideal body type and the schemas and coping strategies associated with it (Hargreaves and Tiggemann 2003). 
Additionally, our results suggest that Amish women may be more inclined to use religious coping strategies to combat body image concerns, which may be not as readably accessible for Catholic and non-religious women. Given that Amish women scored significantly higher on strength of religious faith and religiosity than Catholic and non-religious women, and that religiosity was negatively correlated with scores on the appearance self-evaluation and the avoidance coping strategy in the Amish, religiosity may protect Amish women from focusing on their appearance and incorporating unhealthy coping strategies. Because the Amish are embedded in a community where religion is a central focus (e.g., at work, home, school, etc.), religious coping strategies for body image stressors may be more effective for the Amish than other religious groups who are not as immersed within their religious community. Such an explanation might explain why the use of the religious identity coping strategy positively correlated with life satisfaction in the Amish participants but not in the Catholic participants.

Nevertheless, the Amish lifestyle, which may offer protective effects regarding body image, may also have its risks. For example, Amish women tend to bear more children than Catholic or non-religious women, which in turn may affect the shape of their bodies and their feelings about their appearance (Acheson, 1994; Smith, Alper, Martinez, Gecewicz, and Sciupac, 2015). In fact, several of the Amish women stated that they wished that they could lose their "baby weight" (i.e., weight put on during pregnancies). This is consistent with Platte and colleagues (2000), who reported that Amish women tended to be more dissatisfied with their appearance in older age, which differs from most American women whose body dissatisfaction tends to remain stable across time (Tiggemann 2004). Additionally, it should be noted that nonreligious women were more likely than religious women to use a positive rational acceptance strategy for coping with body image concerns.

\section{Limitations and Future Directions}

This pilot study contains limitations that prevent us for the moment from generalizing these findings. First, the recruitment methods varied across the groups of women. Slightly over half of the Catholic and non-religious participants were recruited through an undergraduate participant pool unavailable to the Amish participants. Related, the Amish women were recruited through outreach in several different Amish communities versus sampling a specific Amish community. Therefore, we cannot generalize these results as indicative of the Amish generally. Second, because the recruited were self-selected, we cannot assume random sampling in tests of statistical significance. Third, we did not ask non-religious women to specify if they were nonaffiliated within religion or agnostic/atheist, though we do know that they scored significantly lower on religiosity measures. Fourth, while we controlled for age in our statistical analyses, our Amish women as a group were older than our non-religious women. Finally, the sample sizes were relatively low. Future studies should address these five limitations.

To the authors' knowledge, this is the first comparative study of Amish body image to other groups and the first study of body image for nearly two decades. This study suggests that relations between religious affiliation, religiosity, and body image are complex. Future research should continue to examine how elements of the Amish lifestyle and religiosity may shield or buffer against Western body image stressors. 


\section{References}

Acheson, Louise. 1994. "Perinatal, Infant, and Child Death Rates among the Old Order Amish." American Journal of Epidemiology 139(2):173-83. https://doi.org/10.1093/oxfordjournals.aje.a116979

Akrawi, Daniel, Roger Bartrop, Ursula Potter, and Stephen Touyz. 2015. "Religiosity, Spirituality in Relation to Disordered Eating and Body Image Concerns: A Systematic Review." Journal of Eating Disorders 3:1-24. https://doi.org/10.1186/s40337-015-0064-0

American Psychiatric Association. 2013. Diagnostic and Statistical Manual of Mental Disorders (5th ed.). Arlington, VA: American Psychiatric Publishing.

Boyatzis, Chris, Sarah Kline, and Stephanie Backof. 2007. "Experimental Evidence that Theistic Religious Body Affirmations Improve Women's Body Image." Journal for the Scientific Study of Religion 46:553-64. https://doi.org/10.1111/j.1468-5906.2007.00377.x

Cash, Thomas, and Patricia Henry. 1995. "Women's Body Images: The Results of a National Survey in the U.S.A." Sex Roles 33:19-28. https://doi.org/10.1007/BF01547933

Cash, Thomas, Susan Melnyk, and Joshua Hrabosky. 2004. "The Assessment of Body Image Investment: An Extensive Revision of the Appearance Schemas Inventory.” International Journal of Eating Disorders 35:305-16. https://doi.org/10.1002/eat.10264

Cash, Thomas, Melanie Santos, \& Emily Williams. 2005. "Coping with Body-image Threats and Challenges: Validation of the Body Image Coping Strategies Inventory." Journal of Psychosomatic Research 58:190-99. https://doi.org/10.1016/j.jpsychores.2004.07.008

Cash, Thomas, and Smolak, Linda. 2012. Body Image: A Handbook of Science, Practice, and Prevention ( $2^{\text {nd }}$ ed.). New York, NY: The Guilford Press.

Chaker, Zina, Felicia Chang, and Julie Hakim-Larson. 2015. "Body Satisfaction, Thin-ideal Internalization, and Perceived Pressure to be Thin Among Canadian Women: The Role of Acculturation and Religiosity." Body Image 14:85-93. https://doi.org/10.1016/j.bodyim.2015.04.003

Chua, Alicia, Stacia DeSantis, Irene Teo, and Michelle Fingeret. 2015. "Body Image Investment in Breast Cancer Patients Undergoing Reconstruction: Taking a Closer Look at the Appearance Schemas Inventory-Revised." Body Image 13:33-37. https://doi.org/10.1016/j.bodyim.2014.12.003

Cohen, Adam, John Pierce, Jacqueline Chambers, Rachel Meade, Benjamin Gorvine, and Harold Koenig. 2005. "Intrinsic and Extrinsic Religiosity, Belief in the Afterlife, Death Anxiety, and Life Satisfaction in Young Catholics and Protestants." Journal of Research in Personality 39:307-324. https://doi.org/10.1016/j.jrp.2004.02.005

Davidson, Denise, Elizabeth Hilvert, Kelly Hughes, and Ieva Misiunaite. 2018. "Evidence for a Threefactor Model Structure of the Appearance Schemas Inventory-Revised in Women." Paper presented at the International Conference on Eating Disorders.

Diener, Ed, Robert Emmons, Randy Larsen, and Sharon Griffin. 1985. "The Satisfaction with Life Scale." Journal of Personality Assessment 49:71-75. https://doi.org/10.1207/s15327752jpa4901_13

Dunkel, Trisha, Denise Davidson, and Shaji Qurashi. 2010. "Body Satisfaction and Pressure to be Thin in Younger and Older Muslin and Non-Muslim Women: The Role of Western and Non-Western Dress Preferences." Body Image 7:56-65. https://doi.org/10.1016/j.bodyim.2009.10.003

Fitzsimmons-Craft, Ellen, Megan Harney, Lisa Brownstone, M. K. Higgins, and Anna Maria BardoneCone. 2012. "Examining Social Physique Anxiety and Disordered Eating in College Women. The Roles of Social Comparison and Body Surveillance." Appetite 59:796-805. https://doi.org/10.1016/j.appet.2012.08.019

Gerber, Lynne. 2008. "Health, Moralization, and Negotiating Judgment in Two Evangelical Ministries." Fieldwork in Religion 3:7-26. 
Gerber, Lynne. 2012. "Fat Christians and Fit Elites: Negotiating Class and Status in Evangelical Christian Weight-loss Culture.” American Quarterly 64:61-84. https://doi.org/10.1353/aq.2012.0011

Giovannelli, Thorayya, Thomas Cash, James Henson, and Erin Engle. 2008. The Measurement of BodyImage Dissatisfaction-Satisfaction: Is Rating Importance Important? Body Image, 5:216-23. https://doi.org/10.1016/j.bodyim.2008.01.001

Good, Merle, and Phyllis Good. 1995. 20 Most Asked Questions about the Amish and Mennonites. Intercourse, PA: Good Books.

Grogan, Sarah. 2007. Body Image: Understanding Body Dissatisfaction in Men, Women and Children ( $2^{\text {nd }}$ ed.). New York, NY: Routledge.

Hairston, Kristen, Julie Ducharme, Margarita Trueth, Wen-Chi Hsueh, Ania Jastreboff, Kathy Ryan, Xiaolian Shi, Braxton Mitchell, Alan Shuldiner, and Soren Snitker. 2013. "Comparison of BMI and Physical Activity between Old Order Amish Children and Non-Amish Children." Diabetes Care 36(April):873-78. https://doi.org/10.2337/dc12-0934

Hargreaves, Duane, and Marika Tiggemann. 2003. "The Effect of 'Thin-Ideal' Television Commercials on Body Dissatisfaction and Schema Activation During Early Adolescence." Journal of Youth and Adolescence 32:367-73. https://doi.org/10.1023/A:1024974015581

Homan, Kristin, and Chris Boyatzis. 2009. "Body Image in Older Adults: Links with Religion and Gender." Journal of Adult Development 16:230-38. https://doi.org/10.1007/s10804-009-9069-8

Homan, Kristin, and Valerie Lemmon. 2016. "Perceived Relationship with God Moderates the Relationship Between Social Comparison and Body Appreciation.” Mental Health, Religion \& Culture 19:37-51. https://doi.org/10.1080/13674676.2016.1140372

Jolly, Natalie. 2014. "Amish Femininity: New Lessons from the Old Order." Journal for the Motherhood Initiative 5:75-89.

Joseph, Stephen, and Deborah Diduca. 2007. "The Dimensions of Religiosity Scale: 20-item Self-Report Measure of Religious Preoccupation, Guidance, Conviction, and Emotional Involvement." Mental Health, Religion \& Culture 10:603-08. https://doi.org/10.1080/13674670601050295

Keel, Patricia, James Mitchell, Traci Davis, and Scott Crow. 2001. "Relationship Between Depression and Body Dissatisfaction in Women Diagnosed with Bulimia Nervosa." International Journal of Eating Disorders 30:48-56. https://doi.org/10.1002/eat.1053

Kraybill, Donald, Karen Johnson-Weiner, and Steven Nolt. 2013. The Amish. Baltimore, MD: Johns Hopkins University Press.

Lyman, Stanford. 1989. The Seven Deadly Sins: Society and Evil. New York, NY: Rowman \& Littlefield.

Mercurio, Andrea, and Laura Landry. 2008. "Self-Objectification and Well-Being: The Impact of SelfObjectification on Women's Overall Sense of Self-Worth and Life Satisfaction." Sex Roles 58:458-66. https://doi.org/10.1007/s11199-007-9357-3

Moradi, Bonnie, and Yu-Ping Huang. 2008. "Objectification Theory and Psychology of Women: A Decade of Advances and Future Directions." Psychology of Women Quarterly 32:377-98. https://doi.org/10.1111/j.1471-6402.2008.00452.x

Moradi, Bonnie, and Julia Varnes. 2017. "Structure of the Objectified Body Consciousness Scale: Reevaluated 20 Years Later." Sex Roles 77:325-37. https://doi.org/10.1007/s11199-016-0731-x

Petrovich, Christopher. 2017. "More Than Forty Amish Affiliations? Charting the Fault Lines." Journal of Amish and Plain Anabaptist Studies 5(1):120-42. https://doi.org/10.18061/1811/81072

Plante, Thomas, and Marcus Boccaccini. 1997. "The Santa Clara Strength of Religious Faith Questionnaire.” Pastoral Psychology 45:375-87. https://doi.org/10.1007/BF02230993 
Platte, Petra, Joan Zelten, and Albert Stunkard. 2000. "Body Image in the Old Order Amish: A People Separate from 'the World'." International Journal of Eating Disorders 8(4):408-14. https://doi.org/10.1002/1098-108X(200012)28:4<408::AID-EAT8>3.0.CO;2-U

Rodin, Judith, Silberstein, Lisa, and Streigel-Moore, Ruth. 1985. "Women and Weight: A Normative Discontent." Pp. 267-307 in Psychology and Gender edited by T. B. Sondereffer. Lincoln: University of Nebraska Press.

Smith, Gregory, Becka Alper, Jessica Martinez, Claire Gecewicz, and Elizabeth Sciupac. 2015. America's Changing Religious Landscape, edited by A. Cooperman. Washington, DC: Pew Research Center. Last accessed December 30, 2018 (http://www.pewforum.org/ 2015/05/12/americas-changingreligious-landscape/).

Stokes, Rachel, and Christina Frederick-Recascino. 2003. "Women's Perceived Body Image: Relations with Personal Happiness." Journal of Women \& Aging 15:17-29. https://doi.org/10.1300/J074v15n01_03

Swami, Viren, Natalie Salem, Adrian Furnham, and Martin Tovée. 2008. "Initial Examination of the Validity and Reliability of the Female Photographic Figure Rating Scale for Body Image Assessment." Personality and Individual Differences, 44:1752-61. https://doi.org/10.1016/j.paid.2008.02.002

Swami, Viren, Stefan Stieger, Amy Harris, Ingo Nader, Jakob Pietschnig, Martin Voracek, ... and Martin Tovée. 2012. "Further Investigation of the Validity and Reliability of the Photographic Figure Rating Scale for Body Image Assessment." Journal of Personality Assessment 94:404-09. https://doi.org/10.1080/00223891.2012.660293

Swami, Viren, Roseanne Taylor, and Christine Carvalho. 2011. "Body Dissatisfaction Assessed by the Photographic Figure Rating Scale is Associated with Sociocultural, Personality, and Media Influences." Scandinavian Journal of Psychology 52. https://doi.org/10.1111/j.14679450.2010.00836.x

Tiggemann, Marika. 2004. "Body Image Across the Adult Life Span: Stability and Change." Body Image 1:29-41. https://doi.org/10.1016/S1740-1445(03)00002-0

Tiggemann, Marika. 2013. "Objectification Theory: Of Relevance for Eating Disorder Researchers and Clinicians?" Clinical Psychologist 17:35-45. https://doi.org/10.1111/cp.12010 